\title{
GENDER PADA RANTAI NILAI PRODUK NELAYAN DI DESA TATELI WERU KECAMATAN MANDOLANG KABUPATEN MINAHASA
}

\author{
Giovana H.P. Tampi'; Jardie A. Andaki²; Christian R. Dien² \\ 1)Mahasiswa Fakultas Perikanan dan IImu Kelautan Universitas Sam Ratulangi Manado \\ 2)Staff Pengajar Fakultas Perikanan dan IImu Kelautan Universitas Sam Ratulangi Manado \\ Koresponden email :giovanatampi28@gmail.com
}

\begin{abstract}
The purpose of this research determine the gender implications of the fishery product value chain in Tateli Weru Village, Mandolang District, Minahasa Regency.

Methode to be used is purposive sampling method in fishermen. Thesimple were taken 10 males and 10 females, both those who worked as fisherman, fish sellers and business administration, the female worked based on their involvement in fishingrelated businesses, fish sellers, processing and administration.

This research can be concluded that thegender aredifferences in each fishery product value chain in Tateli Weru Village. Their activities were equally involved and it can be seen that the role of gender in the division of labour family has settled and male is more extra energy while the important role of female requires precision, patience.
\end{abstract}

Keywords: Gender, value chain, fisheries products, role devision.

\begin{abstract}
Abstrak
Tujuan penelitian ini antara lain mencari berbagai peran, menentukan cara pembagian, menentukan implikasi gender pada rantai nilai produk nelayan di Kecamatan Mandolang Kabupaten Minahasa Desa Tateli Weru.

Pengambilan sampel menggunakan metode purposive sampling yaitu nelayan yang ada di Desa Tateli Weru Kecamatan Madolang Kabupaten Minahasa. Sampel nelayan akan diambil sebanyak 10 laki-laki dan 10 perempuan. Sampel laki-laki diambil baik yang bekerja sebagai nelayan, penjual ikan dan administrasi usaha.Sampel perempuan diambil berdasarkan keterlibatan mereka pada usaha yang berkaitan dengan penangkapan ikan, yaitu penjual ikan, pengeloah ikan dan administrasi usaha.

Penelitian ini dapat disimpulkan bahwa terdapat perbedaan gender pada setiap rantai nilai produk nelayan di Desa Tateli Weru Kecamatan Mandolang.Pada aktivitas penangkapan ikan, peran laki-laki dan perempuan sama-sama ikut terlibat dan dapat dilihat bahwa peran gender dalam pembagian kerja kelurga nelayan memiliki pola yang jelas, tanpa merugikan salah satu pihak.Peranan laki-laki lebih banyak pada pekerjaan yang membutuhkan tenaga ekstra, sedangkan perempuan berperan penting pada pekerjaan ringan sampai sedang, pada karakteristik pekerjaan yang membutuhkan ketelitian, kesabaran dan berulang-ulang.
\end{abstract}

Kata kunci: Gender, rantai nilai, produk nelayan, pembagian peran

\section{PENDAHULUAN}

Mandolang merupakan sebuah kecamatan di Kabupaten Minahasa, Provinsi Sulawesi Utara. Kecamatan Mandolang memiliki 12 desa, tetapi hanya 6 desa saja yang termasuk desa pantai, yaitu: Kalasey, Tateli 1, Tateli 2, Tateli 3, Tateli Weru dan Koha. Berdasarkan ke 6 desa tersebut, maka yang menjadi tempat penelitian yaitu Tateli Weru, karena di desa Tateli Weru memiliki jumlah 105 orang yang bermata pencaharian sebagai nelayan.

Masyarakat di kawasan pesisir sebagian besar berprofesi sebagai nelayan yang diperoleh secara turuntemurun. Karakteristik masyarakat nelayan terbentuk mengikuti sifat dinamis sumberdaya yang digarapnya sehingga untuk mendapatkan hasil tangkapan yang maksimal, nelayan harus berpindah-pindah. Selain itu, resiko usaha yang tinggi meyebabkan masyarakat nelayan hidup dalam suasana alam yang keras yang selalu diliputi ketidakpastian dalam menjalankan usahanya (Sebenan, 2007). 
Permasalahan gender sering dibicarakan dengan menempatkan perempuan sebagai subjek pusat perhatian dalam kajian social, untuk itu perlu antara konsep jenis kelamin (seksual) dan pembedaan seksual (gender) jenis seksual dikenal dengan dua dimensi kategori bersifat biologis, yaitu jenis seksual yang terdiri atas alat (organ) kelamin (vagina dan penis) disertai alat reproduksi masing-masing yang khas. Menurut Budiman (1982), pembagian kerja berdasarkan jenis kelamin (seksual) ialah pembagian kerja atas perbedaan biologis dan sosiokultural, dimana wanita bersifat lemah lembut, bersifat melayani, ketergantungan, emosional, dan tidak bisa bekerja keras, sedangkan laki-laki makhluk yang berjiwa pemimpin, mandiri, kuat, dan rasional, Sehingga laki-laki dan wanita memiliki perannya masing-masing. Berdasarkan latar belakang ini maka perlu dilakukan penelitian guna mengkaji pembagian peran kedudukan, dan tugas antara lakilaki dan perempuan ditetapkan oleh masyarakat berdasarkan sifat perempuan dan laki-laki yang dianggap pantas sesuai norma-norma, adat istiadat, kepercayaan, atau kebiasaan masyarakat.

\section{METODE PENELITIAN}

Penelitian ini dilaksanakan di Tateli Weru Kecamatan Mandolang Kabupaten Minahasa dengan menggunakan pertanyaan terstruktur yaitu berupa kuisioner, kuisioner berisi pertanyaanpertanyaan yang akan diberikan kepada responden untuk mengukur variabelvariabel, berhubungan diantara variabel yang ada serta dapat berupa pengalaman dan pendapat dari responden. Metode survei biasanya digunakan untuk mendapatkan data dari tempat tertentu yang alamiah, tetapi peneliti melakukan perlakuan dalam pengumpulan data (kuesioner, wawancara dan sebagainya), perlakuan yang diberikan tidak sama pada eksperimen.

Metode pengambilan sampel menggunakan purposive sampling untuk mendapatkan nelayan dan anggota kelurga yang terlibat dalam rantai nilai produk nelayan yang ada di Desa Tateli Weru Kecamatan Madolang Kabupaten Minahasa.Purposive Sampling adalah teknik untuk menentukan sampel penelitian dengan beberapa pertimbangan tertentu yang bertujuan agar data yang diperoleh nantinya bisa lebih representative (Sugiyono, 2010).

Data yang diperoleh diolah dan dianalisis secara deskriptif. Menurut Sugiyono (2008), metode analisis deskriptif merupakan metode yang digunakan untuk menganalisis data dengan cara mendeskripsikan atau menggambarkan data yang telah terkumpul sebagaimana adanya tanpa bermaksud membuat kesimpulan yang berlaku untuk umum atau generalisasi. Analisis deskriptif dimaksud untuk memberikan bahasan atau penafsiran terhadap data-data untuk memperoleh kesimpulan.Analisis data deskriptif kualitatif memberikan gambaran keterangan dengan kalimat-kalimat yang dihubungkan dengan teori yang ada, sedangkan deskriptif kuantitatif dilakukan melalui perhitungan sederhana seperti; penjumlahan, rata-rata dan persentase.

\section{HASIL DAN PEMBAHASAN}

\section{Peran dan Pembagian Peran pada Rantai Nilai Produk Nelayan}

Peran gender diciptakan oleh masyarakat tentang laki-laki dan perempuan. Laki-laki dimana melakukan peran dengan mendapat pekerjaan dan 
memperoleh nafkah, sedangkan perempuan berperan menggurus segala sesuatu yang ada di rumah atau bisa dibilang sebagai ibu rumah tangga. Di zaman sekarang peran gender dapat berubah-ubah tergantung kondisi, dan tempat yang berbeda sehingga peran laki-laki dan perempuan dapat dipertukarkan.

Pembagian peran dimana peran laki-laki lebih ke pekerjaan yang membutuhkan tenaga esktra, sedangkan perempuan biasanya berperan penting pada pekerjaan yang ringan.Dalam hal ini peran laki-laki dan perempuan bisa saja berubah, begitu pun dalam pembagian peran mengingat seiring berjalan waktu dimana peran laki-laki sebagai pencari nafkah, perempuan juga sudah turut membantu dalam membangun perekonomian.

\section{Identifikasi Peran dan Pembagian Kerja}

\section{Rantai Nilai Kegiatan Menangkap Ikan}

Kegiatan menangkap ikan dalam rantai nilai merupakan hal pertama yang dilakukan. Di Desa Tateli Weru ini kegiatan penangkapan setiap nelayan memiliki perbedaan waktu dan lamanya nelayan tersebut berada di tengah laut untuk mendapatkan hasil tangkapan. Dalam hal ini juga bagaimana pembagian peran yang akan dilakukan dalam kegiatan penangkapan (Tabel 1).

Tabel 1. Rantai Nilai I Kegiatan Nelayan di Desa Tateli Weru Kecamatan Mandolang.

\begin{tabular}{|c|c|c|c|c|}
\hline No & Kegiatan & Perempuan & $\begin{array}{l}\text { Laki- } \\
\text { laki }\end{array}$ & $\begin{array}{l}\text { Alokasi } \\
\text { waktu }\end{array}$ \\
\hline 1. & $\begin{array}{l}\text { Menyiapkan } \\
\text { konsumsi }\end{array}$ & $\checkmark$ & & $\begin{array}{l}04.30- \\
05.00\end{array}$ \\
\hline 2. & $\begin{array}{l}\text { Menyiapkan } \\
\text { peralatan }\end{array}$ & $\checkmark$ & $\checkmark$ & $\begin{array}{l}04.45- \\
05.00\end{array}$ \\
\hline 3. & $\begin{array}{l}\text { Menyiapkan } \\
\text { perahu }\end{array}$ & & $\checkmark$ & $\begin{array}{l}04.50- \\
05.00\end{array}$ \\
\hline 4. & $\begin{array}{l}\text { Menurunkan } \\
\text { perahu }\end{array}$ & $\checkmark$ & $\checkmark$ & $\begin{array}{l}04.55- \\
05.00\end{array}$ \\
\hline 5. & Melaut & $\checkmark$ & $\checkmark$ & $\begin{array}{l}05.00- \\
16.00\end{array}$ \\
\hline 6. & Merawat alat & & $\sqrt{ }$ & $15.00-$ \\
\hline
\end{tabular}

\begin{tabular}{|r|l|l|r|l|}
\hline & $\begin{array}{l}\text { dan perahu } \\
\text { (temporer) }\end{array}$ & & & 17.00 \\
\hline 7. & $\begin{array}{l}\text { Menurunkan } \\
\text { ikan dari } \\
\text { perahu }\end{array}$ & & $\checkmark$ & $\begin{array}{l}16.00- \\
16.15\end{array}$ \\
\hline 8. & $\begin{array}{l}\text { Mengangkat } \\
\text { ikan ke darat }\end{array}$ & & $\checkmark$ & $\begin{array}{l}16.15- \\
17.00\end{array}$ \\
\hline 9. & $\begin{array}{l}\text { Menyiapkan } \\
\text { ikan dan } \\
\text { menjual ikan }\end{array}$ & $\checkmark$ & & $17.00-$ \\
20.00
\end{tabular}

Sumber: Data Primer (2018)

Pada tabel di atas bisa dilihat pada rantai nilai kegiatan penangkapan bagaimana peran dan pembagian peran yang dilakukan dimana pada penangkapan ikan didominasi oleh lakilaki. Tetapi walau begitu ada peran yang perempuan ikut turut membantu seperti pergi melaut dan menurunkan perahu saat laki-laki akan memulai kegiatan melaût dimna itu biasanya dilakukan oleh laki-laki.

Dalam alokasi waktu kegiatan penangkapan, di Desa Tateli Weru setiap nelayan memiliki waktu melaut yang berbeda, tapi kebanyakan dari mereka waktu melaut yaitu jam 05.00 sampai 17.00 ada juga yang pergi melaut sampai beberapa hari bisa 1 sampai 3 hari. Gambar di bawah ini adalah salah satu kegiatan nelayan saat pergi melaut dan saat kembali setelah selesai melaut.

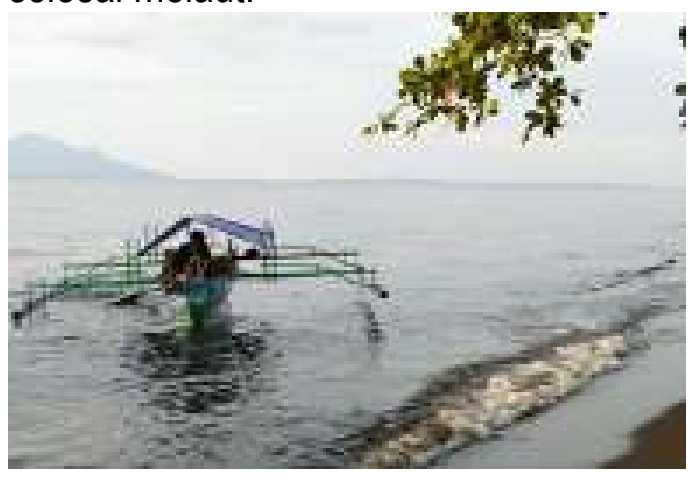

Gambar 1. Nelayan yang Akan Berangkat Melaut 


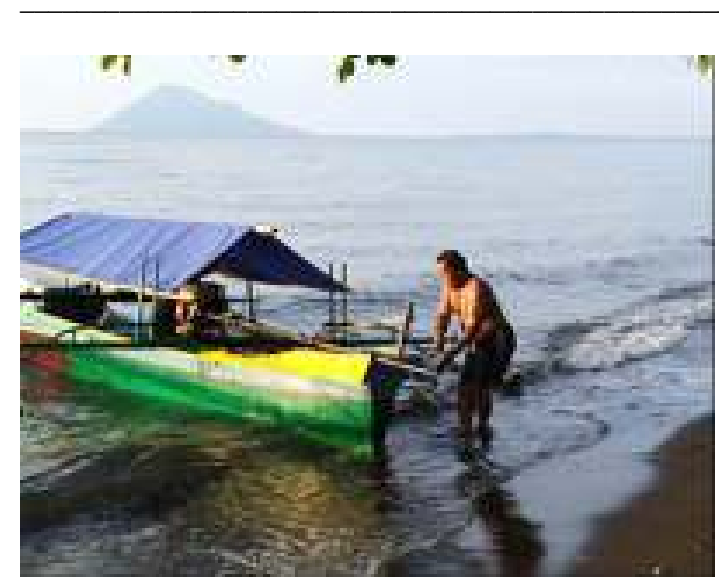

Gambar 2. Nelayan yang Selesai Melakukan Kegiatan Melaut

Gambaran ini menginformasikan keadaan peran, bahwa aktivitas menangkap ikan lebih banyak dilakukan oleh laki-laki.Sedangkan perempuan dalam aktivitas melaut melakukannya ketika suami membutuhkan bantuan untuk melaut bersama.Kondisi ini dapat terjadi bilamana suami tidak mendapatkan teman melaut dari luar keluarga. Alasan lain perempuan melakukan aktivitas melaut jika suami berhalangan karena sakit dan atau ada pekerjaan lain di luar usaha penangkapan ikan.

\section{Rantai Nilai Kegiatan Menjual Ikan}

Kegiatan menjual ikan biasanya dilakukan oleh perempuan baik itu istri nelayan atau anak dari nelayan.Menjual. ikan biasanya dijual di pasar-pasar yang ada untuk memasarkan ikan dan produk ikan dan dalam hal ini kebanyakan perempuan sangat berperan penting dalam kegiatan menjual ikan, tapi ada juga laki-laki yang mengambil peran menjual ikan di pasar.

Dalam hal menjual di rantai nilai memiliki tahap-tahap yang dilakukan sampai pada tahap terakhir yaitu memasarkan ikan. Di Desa Tateli Weru menurut hasil wawancara bahwa yang mengambil peran dalam menjual ikan yaitu perempuan, ada juga yang menyewa orang untuk memasarkan ikan mereka ke pasar, ada juga yang sudah menjadi langganan, dan ada yang dibeli oleh petibo-petibo saat mereka mendaratkan ikan.Tabel berikut menampilkan rantai nilai II, yaitu kegiatan menjual ikan.

Tabel 2.Rantai Nilai Kegiatan Menjual Ikan

\begin{tabular}{|c|l|c|r|r|}
\hline No & \multicolumn{1}{|c|}{ Kegiatan } & Perempuan & $\begin{array}{c}\text { Laki- } \\
\text { laki }\end{array}$ & $\begin{array}{c}\text { Alokasi } \\
\text { waktu }\end{array}$ \\
\hline 1. & $\begin{array}{l}\text { Menyiapkan ikan } \\
\text { untuk dijual }\end{array}$ & $\checkmark$ & 04.00 \\
\hline 2. & $\begin{array}{l}\text { Menyortir ikan } \\
\text { untuk dijual }\end{array}$ & $\checkmark$ & & 04.30 \\
\hline 3. & $\begin{array}{l}\text { Menimbang ikan } \\
\text { untuk dijual }\end{array}$ & $\checkmark 4.35$ \\
\hline 4. & $\begin{array}{l}\text { Menata ikan di cool } \\
\text { box }\end{array}$ & $\checkmark$ & $\checkmark 4.45$ \\
\hline 5. & $\begin{array}{l}\text { Mengangkut ikan } \\
\text { ke mobil }\end{array}$ & $\checkmark$ & & 04.55 \\
\hline 6. & $\begin{array}{l}\text { Menetapkan harga } \\
\text { ikan }\end{array}$ & $\checkmark$ & & 05.00 \\
\hline 7. & $\begin{array}{l}\text { Menjual ikan ke } \\
\text { lokasi desa }\end{array}$ & $\checkmark$ & $\checkmark 05.00$ \\
\hline 8. & $\begin{array}{l}\text { Membawa mobil ke } \\
\text { lokasi }\end{array}$ & $\checkmark$ & $\checkmark 05.00$ \\
\hline
\end{tabular}

Sumber: Data Primer (2018)

Pada Tabel 2 di atas bisa dilihat bagaimana peran dan pembagian peran laki-laki dan perempuan pada rantai nilai kegiatan menjual ikan, dimana peran pada rantai nilai ini didominasi oleh perempuan, dimana mulai dari tahap menyiapkan ikan sampai membawa ikan ke lokasi tempat yang akan dijual perempuan bertanggung jawab atau mengambil peran akan hal ini, walau laki-laki juga ikut turut mengambil peran seperti mengakut ikan ke mobil dan mengantarkan ikan ke lokasi.

Di dalam kegiatan menjual ikan pembagian peran yang dilakukan dimana peran perempuan lebih banyak dari laki-laki. Rantai nilai pada kegiatan menjual ikan dilakukan istri nelayan mulai jam 05.00 pagi dan selesai jam 8 atau jam 9 malam, jika ikan habis dijual jam pulang 04.00 sore. 
Kegiatan menjual ikan dilakukan di pasar teling, pasar karombasan dan ada juga dibeli oleh petibi-petibo.Harga ikan yang dijual jika per 1 ember harga yang ditetapkan Rp. 300.000 dan per tampah dijual dengan harga $\mathrm{Rp}$ 20.000.kendaraan yang dipakai untuk memuat ikan yang dijual ada yang memakai kendaraan sendiri seperti motor dan ada juga kendaraan yang bisa disewa Rp 10.000 untuk membawa ikan ke pasar untuk dijual.

Jika ikan yang dijual di pasar tidak habis terjual maka istri nelayan meletakkan ikan di dalam cool box yang berisi es untuk didinginkan agar bisa dijual kembali pada esok hari.Hal ini dilakukan karena masyarakat yang ada di Tateli Weru tidak memliki kegiatan pengolahan, jadi yang dilakukan yaitu menjual kembali ikan yang tidak laku terjual.

\section{Implikasi dari Pembagian Peran pada Rantai Nilai Produk Nelayan}

Gender adalah perbedaan antara laki-laki dan perempuan dalam peran, fungsi, hak dan tanggung jawab. Seiring berjalannya waktu banyak yang berubah dalam hal pembagian peran, dimana di Desa Tateli Weru peran laki-laki seperti kegiatan melaut bisa juga dilakukan oleh perempuan, selain itu juga kegiatan rumah tangga yang biasa juga dilakukan perempuan bisa juga dilakukan oleh lakilaki.

Implikasi dari pembagian peran pada rantai nilai produk nelayan dapat dilihat pada tabel berikut:

Tabel 3. Implikasi Gender pada Rantai Nilai Produk Nelayan di Desa Tateli Weru Kabupaten Minahasa

\begin{tabular}{|c|c|c|c|}
\hline No & $\begin{array}{c}\text { Jenis } \\
\text { Kegiatan }\end{array}$ & Peran & Implikasi \\
\hline 1. & \multicolumn{3}{|c|}{ Penangkapan ikan } \\
\hline & * Laki-laki & $\checkmark$ & $\begin{array}{l}\text { - Peluang mendapatkan } \\
\text { ikan dari hasil } \\
\text { tangkapan }\end{array}$ \\
\hline & * Perempuan & $\checkmark$ & - Peluang mendapatkan \\
\hline
\end{tabular}

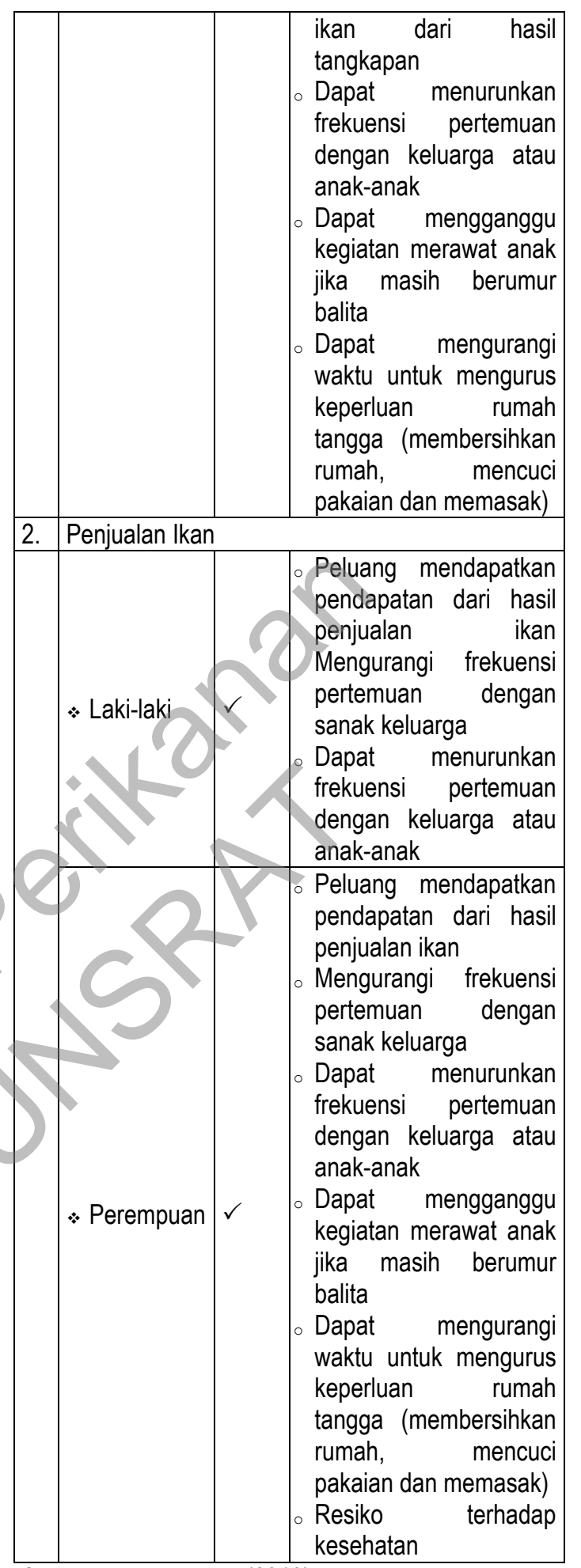

Sumber : Data Primer (2018)

Pada tabel di atas bisa dilihat implikasi dari pembagian peran pada rantai nilai produk nelayan, dimana dalam kegiatan penangkapan peran ini dilakukan oleh laki-laki dan perempuan. Hal ini banyak berbeda dengan daerah 
lain, perempuan selalu tidak terlibat pada kegiatan penangkapan ikan.

Kegiatan penangkapan ikan di Desa Tateli Weru dapat dilakukan oleh perempuan dikarenakan adanya kesempatan untuk melaut yang hanya dilakukan satu hari (one day fishing).Kegiatan melaut jika dilakukan lebih dari satu hari tidak sesuai untuk perempuan, dimana perempuan lebih banyak membutuhkan fasilitas MCK yang tidak dimiliki oleh perahu pada umumnya di Desa Tateli Weru.

Implikasi dari kegiatan penangkapan ikan juga lebih banyak pada perempuan karena perempuan memiliki tugas sebagai ibu rumah tangga.Pekerjaan rumah tangga dapat terbengkalai jika perempuan dalam hal ini ibu rumah tangga memilih untuk ikut dalam aktivitas penangkapan ikan.

Kegiatan menjual ikan lebih banyak dilakukan perempuan yang banyak berperan dalam kegiatan ini dan dalam semua kegiatan dalam rantai nilai produk nelayan, implikasi laki-laki dan perempuan mempunyai keuntungan atau kerugian masing-masing dalam keterlibatan mereka pada kegiatan penangkapan dan kegiatan menjual ikan.

Berdasarkan hasil wawancara dapat dinyatakan bahwa implikasi gender pada kegiatan penangkapan ikan lebih banyak pada perempuan. Hal ini dikarenakan perempuan mempunyai tugas yang lebih banyak terkait dengan perannya di dalam keluarga. Demikian juga gender pada rantai nilai penjualan hasil tangkapan, dimana perempuan juga mendapat implikasi lebih banyak terkait aktivitas penjualan ikan membutuhkan alokasi waktu dan tenaga. Alokasi inilah yang menyebabkan pilihan laki-laki dan perempuan baik sebagai nelayan maupun sebagai penjual ikan, memiliki implikasi yang berbeda.

\section{KESIMPULAN}

Terdapat perbedaan gender pada setiap rantai nilai produk nelayan di Desa Tateli WeruKecamatan Mandolang.Pada aktivitas penangkapan ikan, peran laki-laki dan perempuan sama-sama ikut terlibat dan dapat dilihat bahwa peran gender dalam pembagian kerja kelurga nelayan memiliki pola yang jelas, tanpa merugikan salah satu pihak.Berbagai kendala terkait terganggunya peran ibu rumah tangga, dapat dikompromikan dengan pembagian peran mengurus anak dan kerbesihan serta perawatan rumah tangga kepada anggota keluarga lainnya.Implikasi dalam pembagian peran yang mengarah ke negatif dimana perempuan di Desa tateli Weru terlibat dalam kegiatan penangkapan ikan dimana hal tersebut dapat meganggu atau mempengaruhi perempuan yang memilki tugas sebagai ibu rumah tangga untuk mengurus anak dan rumah.Keterlibatan keluarga seperti (ayah, ibu, kaka, adik, mertua, sepupu) dimana dapat membantu menjaga anak dan mengurus rumah, hal ini bersifat simbolis mutualis.Dalam arti pendapatan yang diperoleh perempuan (ibu rumah) menjadi sumber penghidupan bersama dalam keluarga.

\section{DAFTAR PUSTAKA}

Budiman, A., 1982. "Pembagian Kerja Secara Seksual". Jakarta: Gramedia.

Faller, A., Shunk, D., and Callarman, T., 2006. Value Chains Versus Supply Chains. BPTrends.

Hitt, M.A., and Hoskisson, I.R.D., 2001, Manajemen Strategis, Konsep daya saing dan globalisasi, Buku1, Penerbit Salemba.

Imron, M., 2003.Kemiskinan dalam Masyarakat Nelayan.Dalam Jurnal Masyarakat dan Budaya.PMB-LIPI.

Kusnadi, 2002. Konflik Sosial Nelayan, Kemiskinan dan Perebutan Sumberdaya Perikanan, LKIS, Yogjakarta. 
Kusnadi, 2004. Polemik Kemiskinan Nelayan, Bantul: Pondok Edukasi \& Pokja Pembaruan.

Kusnadi, 2006. Filosofi Pemberdayaan Pesisir, Bandung: Humaniora.

Kusnadi, 2009. Keberdayaan Nelayan Dalam Dinamika Ekonomi Pesisir. Yogyakarta: ArRuzz Media.

Laporan Penelitian Bank Dunia, 2002.Pembangunan Berperspektif Gender, Engendering Development Melalui Perspektif Gender Dalam Hak, Sumberdaya, dan Asprirasi. Laporan Penelitian Bank Dunia, Dian Rakyat. Jakarta.

Moleong L.J., 2005. Metode Penelitian Kualitatif, Bandung, Edisi Revisi, Penerbit PT. Remaja Rosdakarya.

Narimawati, U. 2008. Metodologi Penelitian Kuantitatif dan Kualitatif, Teori dan Aplikasi. Bandung: Agung Media.

Porter, M.E., 2001. Strategi Bersaing, Teknik Menganalisis Industri dan Persaing. Erlangga. Jakarta.

Rahmawati, A., 2004. Persepsi Remaja tentang Maskulin dan Feminim Dilihat dari Beberapa Latar Belakangnya.Skripsi pada jurusan Pendidikan dan Bimbingan UPI Bandung.

Salim, A., 2001. Teori dan Paradigma Penelitian Sosial: Buku Sumber Untuk Penelitian Kualitatif (edisi kedua, Agustus 2006), Tiara.

Satria, dkk., 2014. Hubungan Dukungan Keluarga dengan Tingkat Kecemasan Anak Usia Sekolah yang Menjalani Kemoterapi di Ruang Anyelir RSUD Arifin Achmad Provinsi Riau.
Sebenan, R.D., 2007. Strategi pemberdayaan rumah tangga nelayan di desa gangga II kecamatan Likupang Barat Kabupaten Minahasa Utara.Fakultas Perikanan dan IImu Kelautan, Universitas Sam Ratulangi, Manado.

Sekaran, U., 2011. Metode Penelitian Untuk Bisnis. Jakarta: Salemba Empat.

Subri, M., 2005. Ekonomi Kelautan. Jakarta : Raja Grafindo Persada.

Sugiono, 2008. Metode Penelitian Pendidikan Pendekatan Kuantitatif, Kualitatif dan R dan D. Alfabeta. Bandung.

Sugiyono, 2010. Metode Penelitian Kuantitatif Kualitatif \& RND. Bandung: Alfabeta.

Supardi.M.D., 2006. Metode Penelitian Mataram: Yayasan Cerdas Press.

Undang-Undang Nomor 45 Tahun 2009 tentang Perubahan atas Undang-Undang Nomor 31 Tahun 2004 tentang Perikanan.

USAID, 2010. Guide to Gender Integration and Analysis.

Walgito, B., 2010. Bimbingan dan Konseling (Studi \&Karir). Yogyakarta: Penerbit CV. Andi Offset.

Widodo, J. dan Suadi, 2006. Pengelolaan Sumberdaya Perikanan Laut, Gadjah Mada University Press.

Wignyosoebroto, S., 2005. Desentralisasi dalam Tata Pemerintahan Kolonial Hindia - Belanda: Kebijakan dan Upaya Sepanjang Babak Akhir Kekuasaan Kolonial di Indonesia (1900-1940). Malang: Bayumedia Publishing. 
PS. Agrobisnis Perikanan FPIK UNSRAT

AKULTURASI

Available online :http://ejournal.unsrat.ac.id/index.php/akulturasi

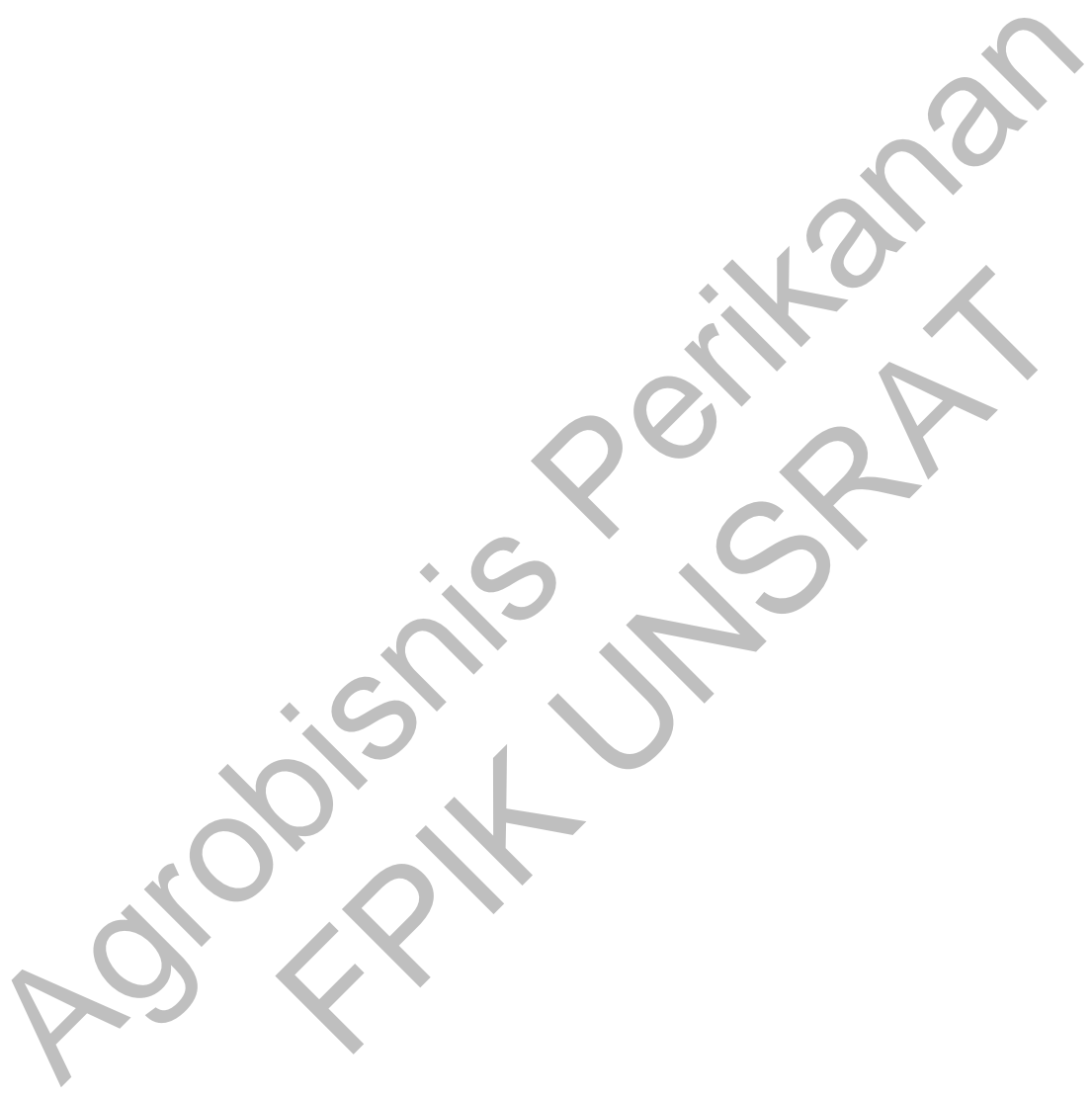

